\title{
The relationship of mindfulness and difficulties in emotion regulation with emotional divorce through sexual satisfaction among married university students in Ahvaz, Iran
}

\author{
Monavar Ghazanfari Shabankare ${ }^{\mathbb{1}}$, Alireza Heidari $^{* *^{\mathbb{D}}}$, Behnam Makvandi $^{\mathbb{(}}$, Fatemeh Sadat Marashian $^{1^{\mathbb{D}}}$ \\ 'Department of Psychology, Ahvaz Branch, Islamic Azad University, Ahvaz, Iran
}

*Corresponding Author: Alireza Heidari, Department of Psychology, Ahvaz Branch, Islamic Azad University, Ahvaz, Iran, Tel: +986133329200, Email: heidaria945@gmail.com

\begin{abstract}
Background and aims: Mindfulness is an important marital predictor that can prevent emotional divorce and improve marital relationships. This study aimed to analyze causal relationships of mindfulness and difficulties in emotion regulation with emotional divorce through sexual satisfaction among married students.

Methods: The current study was a causal-correlational field research. Using convenience sampling method, a total of 211 married students were selected from Islamic Azad University of Ahvaz, Iran in the academic year 2018-2019. The research instrument included the Five Facet Mindfulness Questionnaire (FFMQ), Difficulties in Emotion Regulation Scale (DERS), Emotional Divorce Questionnaire (EDQ), and Sexual Satisfaction Questionnaire (SSQ). Data analysis involved both descriptive and inferential statistics including mean, standard deviation, Pearson correlation, and path analysis. Data analysis was done using SPSS version 24.

Results: A direct and negative relationship was observed between mindfulness and emotional divorce $(\beta=-0.170, P=0.016)$, between difficulties in emotion regulation and sexual satisfaction $(\beta=-0.378, P=0.001)$, and between sexual satisfaction and emotional divorce $(\beta=$ $-0.441, P=0.001)$. There was a direct and positive relationship between mindfulness and sexual satisfaction $(\beta=0.372, P=0.001)$. There was no direct and significant relationship between difficulties in emotion regulation and emotional divorce $(\beta=0.072, P=0.332)$. The path analysis results indicated that sexual satisfaction had a mediating role in the relationship between mindfulness and emotional divorce ( $\beta=-0.149, P=0.001)$, as well as the relationship between difficulties in emotion regulation and emotional divorce $(\beta=-0.080, P=0.002)$. Conclusion: The proposed model had goodness of fit. Sexual satisfaction plays an important role in the relationship between mindfulness, difficulties in emotion regulation, and emotional divorce.

Keywords: Mindfulness, Emotion regulation, Emotional divorce, Sexual satisfaction
\end{abstract}

Received: 5 March 2020, Accepted: 30 May 2020, ePublished: 30 March 2021

\section{Introduction}

Family is the foundation of personal and social life and the main core of a couple's life, so it is essential to take any actions to protect relationships against potential harms. In recent years, the sense of peace of mind has diminished among women and men, and family hearts have faced adverse situations $(1,2)$. Emotional divorce is the first stage of divorce, indicating a declining marital relationship in which the intimacy and unity change into a bitter sense of alienation. In other words, emotional divorce refers to the coldness of couples' relationships (3).

Mindfulness is one of the effective factors in preventing emotional divorce and improving the quality of marital relationships between couples (4). Mindfulness is a balanced mental framework that prevents adverse and emotional catastrophes and provides opportunities in which people experience no adversely emotional states and instability of emotions (5). Mindfulness is a therapeutic technique by which people consider "attending to objectives, being in the present, and forming no judgments" and find out that their lives go on and that their problems can be resolved only in the present $(6,7)$. When people can express themselves without any judgments and reactions, they reach peace of mind in adverse situations. In such situations, peace of mind decreases stress and leads to wellbeing $(8,9)$.

Salehpour et al (10) reported that the emotionally focused mindfulness-based cognitive therapy decreased the irrational beliefs and emotional divorce of married women. Hosseini and Khajooyi Zadeh (11) showed that there was a positive and direct relationship between mindfulness and marital satisfaction in married women and men working in welfare organization.

Difficulties of emotional regulation are characterized by the outbreak of problems in the non-acceptance of emotional responses, difficulty in showing targeted

(C) 2021 The Author(s); Published by Shahrekord University of Medical Sciences. This is an open-access article distributed under the terms of the Creative Commons Attribution License (http://creativecommons.org/licenses/by/4.0), which permits unrestricted use, distribution, and reproduction in any medium, provided the original work is properly cited. 
behavior, difficulty in impulse control, lack of emotional awareness, and low access to emotional regulation strategies (12). In other words, difficulties in emotion regulation are defined as the incidence of problems in awareness, understanding, and accepting emotions, as well as lack of access to adaptive strategies for facing different emotions or inability to control behavior during severe emotional provocations. The ability to regulate personal emotions according to the requirements of special situations is an important human quality. Emotional regulation is the tendency to control inner states, impulses, and behavior, and to adjust them to specific criteria for desired goals. Emotional regulation includes the processes by which people affect their emotions and ways of using their tools (13). The difficulties of emotional regulation cause the use of adaptive and maladaptive strategies to respond to emotions. Unacceptable responses, difficulty in controlling behavior during emotional distress, and deficiency in the efficient use of emotional information are the samples of such strategies (14).

Marital conflicts play significantly mediating roles in the relationships of difficulties in emotion regulation with relationship quality and sexual satisfaction (15). Sexual satisfaction refers to satisfaction (satisfaction with sex), communication (verbal communication and dialogue with spouse such as the easy expression of feelings and feedback on sex) (16), adjustment (couples' awareness of their spouses' sexual needs and efforts for adjustment to spouse in sex), sexual anxiety (women's anxiety about their husbands due to sexual problems and their spouses' sexual relationships with others) $(17,18)$, and personal anxiety (the anxiety about sexual problems and their effects on other aspects of women's life that can prevent their pleasure and peace of mind in their personal life) (19). Since the Iranian society is now in a transition state with traditional rituals, most couples live in traditional families and prefer putting up with very low-quality married lives to experiencing the stress of divorce. Under such circumstances, there are many emotional divorces and independent living cases without any emotion at home. Because of the importance of this issue, this study aimed to address the question whether there was a causal relationship between mindfulness and difficulties in emotion regulation and emotional divorce through sexual satisfaction in married students.

\section{Materials and Methods}

The population of current causal-correlational field research included all the married students studying at Islamic Azad University of Ahvaz, Iran during the academic year 2018-2019. Using convenience sampling method, a total of 211 students (87 males and 124 females) were selected as the samples. Questionnaires were filled with the participants' satisfaction and written informed consent was obtained from all participants. Figure 1 presents the proposed model of research design.

\section{Instruments}

Five Facet Mindfulness Questionnaire (FFMQ): This questionnaire was designed by Baer et al (20), and it has 39 items and five components, namely "being nonreactive", "description", "action with consciousness", and "being non-judgmental". The questionnaire was designed based on a 5-point Likert scale (never= 1 , rarely= 2 , sometimes $=3$, often $=4$, and always $=5)(21)$. There was a positive correlation between mindfulness and five factors of personality, as well as psychological wellbeing, psychological symptoms, and emotional intelligence in some cases, and negative correlations in other cases. In other words, there was a positive and significant correlation between four factors of personality and five facets of mindfulness, except for neuroticism (22). In WatsonSingleton and colleagues' research (23), the reliability of the questionnaire was 0.86 using Cronbach's alpha. In the present study, the Cronbach's alpha coefficient was 0.91 for the questionnaire.

Difficulties in Emotion Regulation Scale (DERS): This scale was designed by Gratz and Roemer (24) to analyze levels of difficulties in emotion regulation. The questionnaire has 36 items and six factors, namely "non-acceptance of emotional responses", "difficulty in applying purposive behavior", "difficulty in impulse control", "lack of emotional awareness", "low access to emotional regulation strategies", and "lack of emotional transparency" (25). Moreover, it is scored based on a 5-point Likert scale from "almost never" to "almost always" (never $=1$, seldom $=2$, almost in half cases $=3$, sometimes $=4$, and almost always $=$ 5) (26). The Cronbach's alpha for this questionnaire was 0.86 (27). In the present study, the Cronbach's alpha coefficient was 0.81 for the questionnaire.

Emotional Divorce Questionnaire (EDQ): This questionnaire has 150 items with five values. Its first section includes 52 items with 5 -value options of very high $=$ score 1 , high $=2$, medium $=3$, low $=4$, and very low $=5$. The second section consists of 43 items with options of totally agree $=$ score 1 , agree $=2$, not agree, not disagree $=3$, disagree $=4$, and totally disagree $=5$. The third section includes 55 items with options of always= 1 , most often $=2$, sometimes $=3$, rarely $=2$, and never $=1$. The Cronbach's alpha was utilized to assess the reliability,

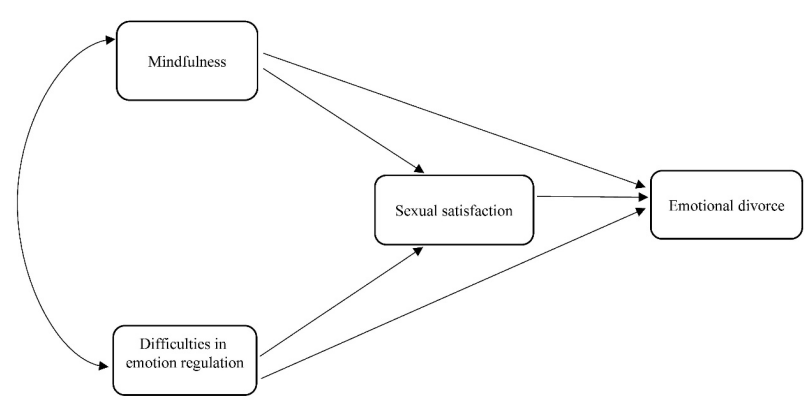

Figure 1. proposed causal model of research. 
and the questionnaire coefficient ranged from 0.60 to 0.82 (28). In the present study, the Cronbach's alpha coefficient was 0.84 for the questionnaire.

Sexual Satisfaction Questionnaire (SSQ): This questionnaire was designed by Hudson et al (29). The questionnaire evaluates the levels of couples' satisfaction and has 25 items. It is a self-report questionnaire (30). The participants' responses to each item were evaluated on a 7 -point scale ranging from 0 to 6 . In general, participants' scores were scored from 0 to 150 in the whole test. A higher score in the questionnaire reflects better sexual satisfaction. The reliability of the questionnaire was reported 0.93 using Cronbach's alpha (30). In the present study, the Cronbach's alpha coefficient was 0.71 for the questionnaire.

\section{Statistical analysis}

Data were analyzed by descriptive and inferential statistics such as mean, standard deviation, minimum and maximum scores, and Pearson's correlation coefficient. Cronbach's alpha coefficient was calculated to determine reliability. The skewness and kurtosis were utilized to specify the normality of data, and the path analysis was used to assess the proposed model. SPSS Amos was further used for analyzing the data. The significance level of research was considered to be $\alpha=0.05$.

\section{Results}

The age range of participants $(n=211)$ was 20-44 years. The demographic variables of the participants are shown in Table 1.

The mean \pm SD scores of emotional divorces, mindfulness, difficulties in emotion regulation, and sexual satisfaction were $44.76 \pm 24.14,53.22 \pm 26.61$, $109.62 \pm 50.26$, and $69.52 \pm 31.03$, respectively. Table 2 presents descriptive statistics including minimum score, maximum score, mean, and standard deviation of research variables.

The one-sample Kolmogorov-Smirnov test indicated the normal distribution of research variables at a confidence level of $95 \%$. Since significance levels of normality statistics were higher than $0.05(P>0.05)$, the scores had normal distribution. Since skewness and kurtosis of research variables were not outside the range of $[-1,+1]$, their data distribution was normal.

Table 3 presents the correlation matrix of research variables, for the path analysis method is based on the correlation of variables. Pearson's correlation coefficients indicated that there was a negative and significant correlation between the mindfulness $(P<0.01, r=-0.559)$ with emotional divorce. There was a positive significant correlation between difficulties in emotion regulation $(P<0.01, \mathrm{r}=0.396)$ with emotional divorce, but a negative and significant correlation between sexual satisfaction $(P<0.05, r=-0.586)$ with emotional divorce. Figure 2 shows an initial proposed model.

According to the data of Table 4, the root means square error of approximation (RMSEA $=0.282$ ) indicated that the initial model needed to be modified. To this end, the

Table 1. Demographic variables of the participants

\begin{tabular}{|c|c|c|}
\hline Demographic variables & No. & $\%$ \\
\hline \multicolumn{3}{|l|}{ Age (y) } \\
\hline $20-24$ & 23 & 10.90 \\
\hline $25-29$ & 63 & 29.86 \\
\hline $30-34$ & 67 & 31.75 \\
\hline $35-39$ & 34 & 16.11 \\
\hline $40-44$ & 24 & 11.38 \\
\hline \multicolumn{3}{|l|}{ Gender } \\
\hline Female & 124 & 58.77 \\
\hline Male & 87 & 41.23 \\
\hline \multicolumn{3}{|l|}{ Marital duration (y) } \\
\hline $1-5$ & 86 & 40.76 \\
\hline $6-10$ & 88 & 41.70 \\
\hline $11-15$ & 20 & 9.49 \\
\hline $16-20$ & 17 & 8.05 \\
\hline \multicolumn{3}{|l|}{ Level of education } \\
\hline Associate's & 16 & 7.58 \\
\hline Bachelor's & 145 & 68.72 \\
\hline Master's & 32 & 15.17 \\
\hline $\mathrm{PhD}$ & 18 & 8.53 \\
\hline
\end{tabular}

Table 2. Descriptive results of research variables

\begin{tabular}{lcccc}
\hline Variables & Min. & Max. & Mean & SD \\
\hline Emotional divorce & 0 & 84 & 44.76 & 24.14 \\
Mindfulness & 15 & 90 & 53.22 & 26.61 \\
Difficulties in emotion regulation & 36 & 180 & 109.62 & 50.26 \\
Sexual satisfaction & 25 & 125 & 69.52 & 31.03 \\
\hline
\end{tabular}

Table 3. Pearson's correlation coefficient between variables

\begin{tabular}{lccc}
\hline Variables & Mindfulness & Emotional divorce & Difficulties in emotion regulation \\
\hline Mindfulness & 1 & & \\
Emotional divorce & $-0.559^{* *}$ & 1 & 1 \\
Difficulties in emotion regulation & $-0.427^{* *}$ & $0.396^{*}$ & $-0.540^{* *}$ \\
Sexual satisfaction & $0.583^{* *}$ & $-0.586^{*}$ & 1 \\
\hline
\end{tabular}

** $P$-value $<0.01$ and $* P$-value $<0.05$ 
relationship between difficulties in emotion regulation and emotional divorce was removed. According to Figure 3 , the root mean square error of approximation (RMSEA) $=0.000, \chi^{2} / d f=0.204$, and comparative fit index $(\mathrm{CFI})=$ 1.00 indicate a good fit of the model.

There was a significant correlation between mindfulness and emotional divorce $(\beta=-0.170, P<0.05)$, and between mindfulness and sexual satisfaction $(\beta=0.372, P<0.01)$; but there was no significant relationship between emotional regulation and emotional divorce (Table 5).

According to the results, there was a significant correlation between difficulties in emotion regulation and sexual satisfaction $(\beta=-0.378, P<0.01)$, and between sexual satisfaction and emotional divorce $(\beta=-0.441$, $P<0.01)$. Bootstrap method was utilized to determine the significance of mediating relations (Table 6). The confidence level indicated the significant indirect path of mindfulness to emotional divorce through sexual satisfaction $(\beta=-0.149, P<0.01)$. Furthermore, there was a significant indirect path of difficulties in emotion regulation to emotional divorce through sexual satisfaction $(\beta=0.80, P<0.01)$.

\section{Discussion}

This study aimed to analyze the causal relationship of mindfulness and difficulties in emotion regulation through sexual satisfaction among married students. According to research results, the proposed model had goodness of fit, and all direct paths were significant except for the difficulties of emotion regulation with emotional divorce. All indirect paths were significant through sexual satisfaction with emotional divorce. The evaluated model had goodness of fit, and it was an important step in identifying effective factors in decreasing emotional divorce. Therefore, the model can be used as an appropriate tool to develop and design programs in order

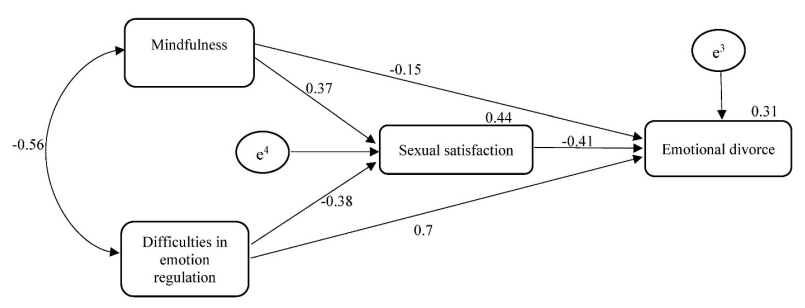

Figure 2. Initial proposed model.

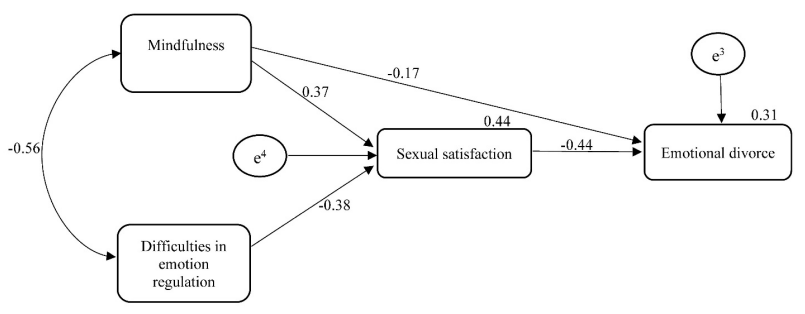

Figure 3. Final modified model.
Table 4. Initial and Final Indicators of Model Fit

\begin{tabular}{lcc}
\hline Fit indicators & Initial model & Final model \\
\hline$\chi^{2}$ & 0.000 & 0.203 \\
$d f$ & 0 & 1 \\
$\left(\chi^{2} / d f\right)$ & - & 0.204 \\
$P$ & - & 0.652 \\
CFI & 0.00 & 1.00 \\
RMSEA & 0.282 & 0.000 \\
\hline
\end{tabular}

to prevent emotional divorce. This finding is consistent with the results of Dalrymple et al (9), Sedaghatkhah and Behzadipour (31) and Sohrabi (15). Many variables directly or indirectly affect the couples' quality of life and the frequency of conflicts between them. One of these variables is their emotions. The quality of emotions, as the most important factor in the relationships, can predict marital satisfaction (32). According to the discussed role of mindfulness in emotional divorce, people who experience higher levels of mindfulness focus on the present as well as internal and external stimuli more often than those who experience lower levels of mindfulness. Mindfulness refers to the non-judgmental observation of thoughts and emotions. People with mindfulness abilities and skills know that thoughts are not actions; thus, they are aware of destroying the nature of some thoughts that cause fear of failure and disappointment in them. Therefore, they obtain more awareness of thoughts and emotions, and are less affected by negative and destructive thoughts and unfavorable emotions. As a result, they are less likely to experience the emotional divorce (33).

Various emotion regulation strategies can be used in different stages of an emotional reaction (34). Thus, it seems that emotion regulation done by couples can increase their adaptive capabilities and enhance their marital satisfaction. Couples need to learn how to calm down the situation, regain their calmness, and focus on the problem again. They also have to discover how to adjust their intense emotions to different stressful situations (35). Hence, the attention paid to the role of emotion regulation in peoples' coping capacity brought about the researcher's curiosity to examine the effects of emotion regulation strategies on the reduction of marital conflicts (32). Couples with emotional divorce and lower mindfulness levels have fear of failure, low self-esteem and self-efficiency, and no hope in the future, and they are pessimistic about future of marriage. In fact, their minds are full of judgmental and negative thoughts that prevent their constructive activities; therefore, they are unable to have intimate relationships with their spouses. As a result of these thoughts which are reactive, judgmental and self-criticizing people lose their incentives to establish intimate relationships with their spouses, even though they know that they should take necessary steps towards achieving goals and success. People with further problems in brain/cognitive inhibition 
Table 5. Path coefficients of direct effects between research variables in the initial and final models

\begin{tabular}{|c|c|c|c|c|c|c|}
\hline \multirow{2}{*}{ Path } & \multicolumn{3}{|c|}{ Initial model } & \multicolumn{3}{|c|}{ Final model } \\
\hline & Path type & $\beta$ & $P$ value & Path type & $\beta$ & $P$ value \\
\hline Mindfulness and emotional divorce & Direct & -0.146 & 0.050 & Direct & -0.170 & 0.016 \\
\hline Mindfulness and sexual satisfaction & Direct & 0.372 & 0.001 & Direct & 0.372 & 0.001 \\
\hline Difficulties in emotion regulation and emotional divorce & Direct & 0.072 & 0.332 & Direct & - & - \\
\hline Difficulties in emotion regulation and sexual satisfaction & Direct & -0.378 & 0.001 & Direct & -0.378 & 0.001 \\
\hline Sexual satisfaction and emotional divorce & Direct & -0.412 & 0.001 & Direct & -0.441 & 0.001 \\
\hline
\end{tabular}

Table 6. Results of the bootstrap method for investigating indirect and intermediary paths

\begin{tabular}{|c|c|c|c|c|c|c|}
\hline \multirow{2}{*}{ Predictor variable } & \multirow{2}{*}{ Mediator Variable } & \multirow{2}{*}{ Criterion variable } & \multicolumn{2}{|c|}{ Initial model } & \multicolumn{2}{|c|}{ Final model } \\
\hline & & & Bootstrap & $P$ value & Bootstrap & $P$ value \\
\hline Mindfulness & Sexual satisfaction & Emotional divorce & -0.139 & 0.001 & -0.149 & 0.001 \\
\hline Difficulties in emotion regulation & Sexual satisfaction & Emotional divorce & 0.072 & 0.002 & 0.080 & 0.002 \\
\hline
\end{tabular}

experience more difficulties in emotional regulation. People who are unable to stop their thoughts, emotions, and irrelevant information will be unable to identify the dynamic flow of emergence and growth of emotion; hence, they have difficulty with emotional awareness. In fact, people without emotional regulation have difficulty in considering, describing, and identifying their own and others' emotions (36). Mindfulness techniques provide a way to deal with daily stressful situations (32). Stressors within the family are part of life and sometimes impossible to change; however, ways to deal with or respond to them can change. Since marital conflicts are significantly related to daily stresses and faulty automatic thoughts, regular mindfulness exercises can create positive changes in some of the couple relationships and consequently enhance their marriage (37).

Difficulties with emotion regulation can lead to the use of maladaptive strategies for responding to emotions (38). The non-acceptance of emotional responses, difficulty in controlling behavior during emotional distress, lack of emotional transparency, low access to emotional strategies, and deficiency in the efficient use of emotional information are some cases of this strategy (39). Since emotional divorce needs cognitive and emotional adaptive strategies for inhibition, people with difficulty in regulating their emotions spend so much time getting into disputes and keeping distance from their spouses, whereas they spend little time solving emotional problems in their marital lives; hence, such couples are prone to emotional divorce. According to the relationship between sexual satisfaction and emotional divorce, sexual satisfaction refers to couples' satisfaction with sex and their abilities to have satisfactory sex with their spouses. Sexual satisfaction is a pleasant experience for a person or spouse during any stage of normal sex, including the desire, excitement, or arousal. Therefore, the couples who have no timely and high-quality sex and do not attempt to help their spouses reach orgasm will have problems such as emotional divorce in their marital lives.

\section{Conclusion}

Sexual satisfaction plays an important role in the relationship between mindfulness, difficulties in emotion regulation, and emotional divorce. Mindfulness exercises can create positive changes in some of the couple relationships and consequently enhance their marriage. The results of this study provided important information about the effectiveness of mindfulness and emotion regulation training in increasing sexual satisfaction. In this study, a major research limitation was its cross-sectional nature and causal explanation of correlation studies. Moreover, the research sample included the married students of Islamic Azad University of Ahvaz; hence, it was difficult to generalize the results to other groups and populations.

Conflict of Interests

All authors declared no personal or financial conflict of interests.

Ethical Approval

The participants willingly filled out the questionnaires and signed written informed consent. The study was approved by the Ethics Committee of Islamic Azad University, Ahvaz branch (code: IR.IAU. AHVAZ.REC.1396.094).

Authors' Contribution

MGS: Study concept and design, acquisition of data, analysis and interpretation of data, and statistical analysis. $\mathrm{AH}$ and BM: Administrative, technical, and material support, and study supervision. FSM: Critical revision of the manuscript for important intellectual content.

Funding/Support

None.

Acknowledgements

This article was extracted from a part of the PhD dissertation of Monavar Ghazanfari Shabankare in the Department of Psychology, Ahvaz Branch, Islamic Azad University, Ahvaz, Iran during the academic year 2018 (code: 950330003). The researchers wish to 
thank all the individuals who participated in the study.

\section{References}

1. Hashemi SF, Asghari Ebrahimabad MJ. The role of emotional literacy in the prediction of emotional divorce by mediation conflict resolution. Journal of Excellence in Counseling and Psychotherapy. 2016;5(17):59-72. [Persian].

2. Fakhri M, Mahdavianfard R, Kimiaee SA. Prediction of the probability of divorce based on avoidant attachment, anxiety attachment and family problem solving skills. Counseling Culture and Psycotherapy. 2018;9(33):207-22. doi: 10.22054/ qссрс.2018.28605.1716. [Persian].

3. Hadjizadeh Meimandi M, Madahi J, Karimi Y, Hedat E, Ghorouri M. A study of the related social factors with emotional divorce (population study; married in Shiraz). Women's Strategic Studies. 2016;18(71):85-108. doi: 10.22095/jwss.2016.33833. [Persian].

4. Creswell JD. Mindfulness Interventions. Annu Rev Psychol. 2017;68:491-516. doi: 10.1146/annurevpsych-042716-051139.

5. Azadi MM, Manshaee G, Golparvar M. Comparing the effectiveness of mobile social network-based mindfulness intervention with acceptance and commitment therapy and mindfulness therapy on self-management and glycated haemoglobin level among patients with type 2 diabetes. J Shahrekord Univ Med Sci. 2019;21(5):221-8. doi: 10.34172/ jsums.2019.39.

6. Kudesia RS. Mindfulness as metacognitive practice. Acad Manage Rev. 2019;44(2):405-23. doi: 10.5465/ amr.2015.0333.

7. Baker BM, Saari A. 'The anatomy of our discontent': from braining the mind to mindfulness for teachers. Discourse: Studies in the Cultural Politics of Education. 2018;39(2):16983. doi: 10.1080/01596306.2018.1394425.

8. Schneider J, Malinowski P, Watson PM, Lattimore P. The role of mindfulness in physical activity: a systematic review. Obes Rev. 2019;20(3):448-63. doi: 10.1111/obr.12795.

9. Dalrymple KL, Clark H, Chelminski I, Zimmerman M. The interaction between mindfulness, emotion regulation, and social anxiety and its association with emotional eating in bariatric surgery candidates. Mindfulness. 2018;9(6):1780-93. doi: 10.1007/s12671-018-0921-4.

10. Salehpour P, Ahghar G, Navabi Nejad S. The Effectiveness of Mindfulness-Based Cognitive Therapy on Reducing Irrational Beliefs and Emotional Divorce in Married Women Referred to Tehran Counseling Centers. Med J Mashhad Univ Med Sci. 2019;62:169-78. doi: 10.22038/mjms.2020.14314. [Persian].

11. Hosseini SO, Khajooyi Zadeh Z. The Relationship between Mindfulness and Marital Satisfaction among Married Women and Men Working in the Kurdistan Welfare Organisation. Family Pathology, Counseling and Enrichment Journal. 2015;1(2):14-24. [Persian].

12. Berke DS, Reidy DE, Gentile B, Zeichner A. Masculine discrepancy stress, emotion-regulation difficulties, and intimate partner violence. J Interpers Violence. 2019;34(6):1163-82. doi: 10.1177/0886260516650967.

13. Jarrett NL, Yamane DE, Gildner DJ, Pickett SMThe Indirect Effect of Sleep Quality on Emotional Exhaustion through Emotion Regulation Difficulties and Perceived Stress in a Sample of U.S. Medical Students. Sleep. 2019;42(Suppl_1):A87. doi: 10.1093/sleep/zsz067.211.

14. Bardeen JR, Fergus TA, Hannan SM, Orcutt HK. Addressing psychometric limitations of the Difficulties in Emotion Regulation Scale through item modification. J Pers Assess. 2016;98(3):298-309. doi: 10.1080/00223891.2015.1091774.
15. Sohrabi N. Mediating role of marital conflicts for cognitive emotional regulation and quality of sextual relationship. Biannual Journal of Applied Counseling. 2015;4(2):37-48. doi: 10.22055/jac.2015.12596. [Persian].

16. Luk BH, Loke AY. The impact of infertility on the psychological well-being, marital relationships, sexual relationships, and quality of life of couples: a systematic review. J Sex Marital Ther. 2015;41(6):610-25. doi: 10.1080/0092623x.2014.958789.

17. Chattopadhyay $\mathrm{S}$. The responses of health systems to marital sexual violence-a perspective from Southern India. J Aggress Maltreat Trauma. 2019;28(1):47-67. doi: 10.1080/10926771.2018.1494235.

18. Moradi I, Fatehizade M, Ahmadi A, Etemadi O. Wives' perception of sexual relationship with narcissistic men: results of a qualitative thematic analysis with Iranian women. J Shahrekord Univ Med Sci. 2019;21(3):137-43. doi: 10.34172/ jsums.2019.24.

19. Roshan Chesli R, Mirzaei S, Nikazin A. Validity and reliability of multidimensional sexual satisfaction scale for women (SSSW) in one sample of Iranian women. Clinical Psychology and Personality. 2014;12(1):129-40. [Persian].

20. Baer RA, Smith GT, Hopkins J, Krietemeyer J, Toney L. Using self-report assessment methods to explore facets of mindfulness. Assessment. 2006;13(1):27-45. doi: 10.1177/1073191105283504.

21. Geiger PJ, Herr NR, Peters JR. Deficits in mindfulness account for the link between borderline personality features and maladaptive humor styles. Pers Individ Dif. 2019;139:19-23. doi: 10.1016/j.paid.2018.10.035.

22. Ahmadvand Z, Heydarinasab L, Shairi MR. An investigation of the validity and reliability of psychometric characteristics of five facet mindfulness questionnaire in Iranian non-clinical samples. Int J Behav Sci. 2013;7(3):229-37. [Persian].

23. Watson-Singleton NN, Walker JH, LoParo D, Mack SA, Kaslow NJ. Psychometric evaluation of the Five Facet Mindfulness Questionnaire in a clinical sample of African Americans. Mindfulness. 2018;9(1):312-24. doi: 10.1007/s12671-0170776-0.

24. Gratz KL, Roemer L. Multidimensional assessment of emotion regulation and dysregulation: development, factor structure, and initial validation of the difficulties in emotion regulation scale. J Psychopathol Behav Assess. 2004;26(1):41-54. doi: 10.1023/b:joba.0000007455.08539.94.

25. Kiel EJ, Viana AG, Tull MT, Gratz KL. Emotion socialization strategies of mothers with borderline personality disorder symptoms: the role of maternal emotion regulation and interactions with infant temperament. J Pers Disord. 2017;31(3):399-416. doi: 10.1521/pedi_2016_30_256.

26. Besharat MA, Khalili Khezrabadi M, Rezazadeh SM. The mediating role of difficulty of emotion regulation in the relationship between early maladaptive schemas and marital problems. Fam Psychol. 2017;3(2):27-44.

27. Sepehri Nezhad M, Hatamian P. The prediction of academic burnout based on the emotion dysregulation and social support in nursing students. Education Strategies in Medical Sciences. 2018;11(1):59-65. doi: 10.29252/edcbmj.11.01.08. [Persian].

28. Zamani S, Ahadi H, Asgari P. Relationship of emotional divorce with body image and perfectionism. Journal of Psychological Studies. 2015;10(4):119-36. doi: 10.22051/psy.2015.1789. [Persian].

29. Hudson WW, Harrison DF, Crosscup PC. A short-form scale to measure sexual discord in dyadic relationships. J Sex Res. 1981;17(2):157-74. doi: 10.1080/00224498109551110.

30. Talayizadeh F, Bakhtiyarpour S. The relationship between 
marital satisfaction and sexual satisfaction with couple mental health. Thoughts and Behavior in Clinical Psychology. 2016;11(40):37-46. [Persian] .

31. Sedaghatkhah A, Behzadipour S. Predicting the quality of marital relationship on the base of relationship beliefs, mindfulness and psychological flexibility. Quarterly Journal of Women and Society. 2017;8(30):57-77. [Persian].

32. Molajafar H, Mousavi SM, Lotfi R, Seyedeh Madineh G, Falah $M$. Comparing the effectiveness of mindfulness and emotion regulation training in reduction of marital conflicts. J Med Life. 2015;8(Spec Iss 2):111-6.

33. Ghasemi Jobaneh R, Mousavi SV, Zanipoor A, Hoseini Seddigh MA. The relationship between mindfulness and emotion regulation with academic procrastination of students. Education Strategies in Medical Sciences. 2016;9(2):134-41. [Persian].

34. Fancourt D, Ali H. Differential use of emotion regulation strategies when engaging in artistic creative activities amongst those with and without depression. Sci Rep. 2019;9(1):9897. doi: 10.1038/s41598-019-46138-3.
35. Omidi A, Talighi E. Prediction couple's marital satisfaction based on emotion regulation. Int J Educ Psychol Res. 2017;3(3):157-62. doi: 10.4103/2395-2296.204120.

36. Hosseini FS, Omidvar Y, Abbasi N. The role of executive functions and negative automatic thoughts in difficulties of emotion regulation in adolescent. Clinical Psychology Studies. 2017;7(26):83-111. doi: 10.22054/jcps.2017.7393. [Persian].

37. Timmons AC, Arbel R, Margolin G. Daily patterns of stress and conflict in couples: associations with marital aggression and family-of-origin aggression. J Fam Psychol. 2017;31(1):93104. doi: $10.1037 /$ fam0000227.

38. Short NA, Boffa JW, Clancy K, Schmidt NB. Effects of emotion regulation strategy use in response to stressors on PTSD symptoms: an ecological momentary assessment study. J Affect Disord. 2018;230:77-83. doi: 10.1016/j.jad.2017.12.063.

39. Besharat MA, Shahidi V. Mediating role of cognitive emotion regulation strategies on the relationship between attachment styles and alexithymia. Eur J Psychol. 2014;10(2):352-62. doi: 10.5964/ejop.v10i2.671. 